\title{
Developing a postgraduate work-based curriculum using an Intervention Mapping
}

\section{Approach}

\author{
*Victoria Stewart, Matthew Campbell, Amanda. J. Wheeler
}

\section{(Abstract)}

Advanced practitioner skill development has become an important focus in health service delivery as increasingly complex consumer needs, practice environments, and national professional registration requirements impact on professional work practices. Increasingly, work-based or workplace learning experiences are being seen as an effective means for maintaining skill currency across working lives. Currently there is limited literature on pedagogical practices to support the educational and training requirements associated with development across a person's working life. This paper reports on an example of how an intervention mapping framework was used to guide the development, implementation and evaluation of a work-based praxis course for students in an interprofessional, on-line postgraduate mental health program. The intervention mapping framework provided a stepped process to guide decision making and allowed the incorporation of theory and evidence into the course design. This approach provided a stepped process to guide decision making and allowed the incorporation of theory and evidence into the course design. While the use of the intervention mapping framework is often used within health promotion arenas, particularly for the effective design of health promotion educational programs, it is argued that this framework can be utilised effectively when developing curriculum for use within higher education programs.

Keywords: Work-based learning, postgraduate, curriculum design, Intervention Mapping, mental health, advanced practitioner

\section{Introduction}

Mental illnesses are the largest single cause of disability in Australia, accounting for $24 \%$ of the burden of non-fatal disease (Begg et al., 2007). An estimated 3\% of Australian adults have severe and chronic psychiatric disorders and service provision for this group accounts for about $80 \%$ of Australia's spending on mental health care (Australian Institute of Health and Welfare, 2012). As a result, mental health service reform has remained a Government priority and the need for ongoing mental health workforce development, education and training has been recognised as crucial in the success of this reform. There are

\footnotetext{
*Email: v.stewart@griffith.edu.au
} 
emerging concerns about the capacity of the existing mental health workforce in Australia to meet current service delivery needs (Health Workforce Australia, 2011).

As the concepts of competence, knowledge production and lifelong learning become increasingly important in professional discourse, research and higher education needs to respond innovatively. The nature of mental health work and professional practice are constantly changing due to a multitude of factors such as increasingly complex consumer needs, rapidly changing practice environments, national professional registration requirements and advancing technologies (Higgs, Loftus, \& Trede, 2010). There is an increasing requirement for a multi-skilled, flexible workforce, able to work in a variety of settings and to respond to a range of tasks (Cairns \& Malloch, 2011). Barnett (2012) identifies the 'supercomplexity' of this new world order and argues the importance of understanding ourselves and our sense of identity within the world. Professional identity formation is no longer an undergraduate outcome, but rather a lifelong phenomenon (Trede \& McEwen, 2012). Professionals are now seeing continuing professional education as an opportunity to combine work and study to enhance expertise, critically reflect upon and transform practice (Orrell \& Higgs, 2012). Universities, particularly in consideration of postgraduate qualifications, must respond effectively to continuing education needs, and through partnerships with industry, community stakeholders and students design curriculum to promote lifelong learning (Orrell \& Higgs, 2012; Plewa, Galán-Muros, \& Davey, 2014). There is, therefore, a purposeful role for universities to undertake in the facilitation of continuing professional education, but this role must be in partnership with a range of other stakeholders.

In response to these changing mental health workforce demands, a postgraduate, interprofessional mental health practice program (consisting of a Graduate Certificate and Masters qualification) was developed and introduced at Griffith University, in 2009. This online program aims to provide health professionals with advanced knowledge and skills in mental health practice and respond to emerging workforce needs. The program attracts students from a diverse range of health professional backgrounds (such as nursing, social work, psychology, occupational therapy) and work environments (such as clinical, nongovernment, private practice). A review of the program was undertaken in 2011 that identified that work-based placements, due to their focus on practice skills, discipline-specific learning and workplace translation were highly valued by both students and employers (Stewart, Fielden, Harris, \& Wheeler, 2012). From this evaluation, it was clear that a work- 
based course, designed to meet the needs of advanced practitioners from different professional backgrounds would be an important element in the program.

The nature of adult learning and its relationship with the work environment is gaining interest within the higher education sector (Kerry \& Kerry, 2010). Work-based learning is seen as one important mechanism to provide adult learners with learner-led education which is relevant to their educational goals and provides them with skills to continue to learn across their working lives (Raelin, 2007). Work-based learning refers to the formalisation of learning at work and refers to all and any learning that is situated in the workplace (Lester \& Costley, 2010). The label of work-based learning, as opposed to work-integrated learning or clinical placements, is used in this paper to emphasise both the location of learning and also the ongoing embedded nature of learning in professional settings.

Work-based learning opportunities have been incorporated into health practitioner higher education programs for many years and have traditionally been provided in the form of placements, in which there is a focus on base competence acquisition and assessment. Within postgraduate, advanced practice programs, many of the students are already working in their area of specialisation and traditional placements in alternative workplaces, are not seen as a suitable option for the development of advanced clinical skills. There are advantages to students being able to engage in work-based learning experiences at an advanced level to promote the development of new forms and understandings of practice (Fowler \& McGarry, 2011). However, the development of rigorous pedagogies to underpin work-based learning and its assessment is still embryonic (Brodie \& Irving, 2007), particularly for use within postgraduate programs.

\section{An Intervention Mapping Approach and curriculum design}

This article outlines the process utilised in the development of work-based curriculum (a praxis course) to enhance advanced mental health practitioner skills within an on-line postgraduate program. Curriculum is critical in providing high quality educational programs, however little attention has been given to the evolution of curriculum, its review and transformation in higher education (Khan \& Law, 2015). To ensure that universities thrive in a complex environment, Weller (2012) advocates for a scholarly approach to curriculum design, delivery and evaluation; one in which all stakeholders can be engaged (Healy, Perkmann, Goddard, \& L., 2014; Kandiko \& Blackmore, 2012). The authors sought a 
structured approach to guide the development of this new curriculum and the Intervention Mapping approach (Bartholomew, Parcel, \& Kok, 2010) was identified.

Intervention Mapping has traditionally been used in the development of health promotion programs (Cornélio et al., 2013; Dalum, Schaalma, \& Kok, 2012; Kok, Schaalma, Ruiter, Van Empelen, \& Brug, 2004; Lloyd, Logan, Greaves, \& Wyatt, 2011) and health interventions (Munir, Kalawsky, Wallis, \& Donaldson-Feilder, 2013; van Oostrom et al., 2007), but there has been recent interest in the use of this approach in the development of training and education programs (van Rijssen, Schellart, Anema, de Boer, \& van der Beek, 2011; Wheeler, Fowler, \& Hattingh, 2013). Bartholomew et al. (2010) describes three essential elements or core processes when using the Intervention Mapping approach which include the use of evidence and empirical findings, accessing and using theory and collecting and using new data.

Intervention Mapping is a planning framework which outlines the developmental process or steps which inform and develop an intervention. Existing literature, appropriate theories and stakeholder data are all systematically utilised and applied during the steps of the program development (Bartholomew et al., 2010). The Intervention Mapping approach comprises of six steps or phases which are: i) needs assessment; ii) mapping of program objectives; iii) theory-based methods and practical strategies; iv) program design; v) adoption and implementation plan; and vi) evaluation plan. The steps, or phases, are not a linear process; instead they need to be considered as an iterative process of ongoing engagement and development of concept and behaviour informed through evidence, theory and data. The following provides an overview of how the Intervention Mapping Framework was used to guide and inform the development of a work-based curriculum (praxis) for advanced mental health practitioner skills. This is presented as a discussion of the six steps of the approach and how they are applied to the particular context of developing a work-based learning curriculum for advanced mental health practitioners. Within each step, analysis of the underlying approach is provided, highlighting key steps undertaken in the use of such an approach in the design of a Master of Mental Health Practice workplace experience. This paper aims to explain how the framework of Intervention Mapping for curriculum design was utilised and how this approach could be applied in other fields.

\section{Step 1: Praxis needs assessment}


The word 'praxis' dates back to the ancient Greeks and Aristotle, who defined it in terms of practical knowledge and action. 'The Greek word praxis means action, practice, habit, cultural tradition and form of life'(Mattsson \& Kemmis, 2007, p. 187). Within nursing literature, the use of praxis is often used to convey the moral imperative of nursing practice a focus on professional deliberation rather than a rationalistic-technical way of working (Connor, 2004). Reflective practice is often associated with praxis and suggests that in addition to what one does, it is also important to understand what one thinks about and what others do (Raelin, 2007). Reflection can be seen as a means to make sense of an experience in situations that are complex, and which do not lend themselves to being simplified by the use of concepts and frameworks that can be taught (Boud, 2010). Within work-based learning, it seems important that reflective practice is seen as an important element in learning and the development and translation of knowledge into practice.

Within nursing literature, praxis is seen to be not only about professional actions but also an ongoing reflective activity in terms of consequences and evaluation of these actions with the aim of refining knowledge and future nursing practices (McCormack \& Manly, 2004). Generally, knowledge is constantly being remade through the process of praxis and it is for this reason, the course in development was given the title of Mental Health Praxis.

To fully understand praxis within a field of professional practice it is imperative to assess the experience of practitioners. The first step in undertaking curriculum design using Intervention Mapping was to identify the needs of stakeholders. Stakeholders (in the form of membership of a Reference Group) were identified through a purposive sampling method allowing the identification of individuals who would be most informative in providing advice and recommendations on pedagogical models for the development of advanced practitioner skills. The Group consisted of eight members from the following three identified stakeholder groups: i) senior mental health professionals in supervisory roles within the mental health workforce $(n=2)$; ii) academic staff within higher education responsible for the development of curriculum for the mental health workforce $(n=3)$; and iii) academic staff with a role in the leadership of work-integrated learning programs within higher education $(n=3)$.

A discussion schedule was constructed, asking the members to provide information and advice regarding the learning needs of advanced practitioners, curriculum design and construction to meet these needs, how best to provide this curriculum in an on-line learning environment and appropriate assessment items to evaluate student outcomes. The Reference 
Group discussions identified the following issues that would need to be addressed by the course design:

- Due to the diverse student cohort and differences in student activities, workplaces and work roles, it was essential that the assessment items identified outcomes for each individual;

- Assessment items to measure growth in capability for each individual student;

- Assessment to focus on the application of skills;

- Learning goals to be context-specific and aligned to workplace requirements.

In addition to exploration with stakeholders there is a need to qualify these experiences through a broader exploration of literature. In the process of curriculum design a literature review/scan was conducted to identify how work-based curriculum is used within the higher education sector to promote advanced practitioner skills development and explore pedagogical models currently utilised within curriculum. Current work-based courses and curriculum resources were also reviewed to identify current educational practices. Keywords such as practice learning, praxis, work-based learning, work-integrated learning, professional practice, health education, expertise and lifelong learning were searched and texts and articles identified. These literature sources were reviewed and additional sources identified from the reference lists.

The literature review identified (i) increasing concern that learning in higher education needs to align better with the practice of the occupation, and (ii) an acceptance that a focus on knowledge acquisition itself is not sufficient to produce long-term proficient practitioners (Hager, 2011). Current research (Billett, 2008, 2010, 2011a; Morris \& Blaney, 2010; Smith, 2011 ) is focusing on the pedagogic and curriculum potentials of workplaces and work experiences, particularly how workers engage in workplace practices, and how interaction with aspects of the workplace, shapes and forms learning opportunities. Increasingly, workplace learning experiences are being seen as an effective means for maintaining skill currency across working lives (Raelin, 2007), and interest in work-based learning is expanding to situations outside the undergraduate, preparatory workplace experience.

In addition, education for future professional practice has become an interdependent undertaking between higher education, workplaces, industry partners, regulatory agencies, professional bodies, students and society. The development of new forms and 
understandings of practice is a clear advantage to students who engage in work-based learning experiences. Fowler and McGarry (2011) identify that within nursing education, clinical and practice settings are productive places for the generation of knowledge. The constantly changing nature and complexity of practice situations allows for situated knowledge generation and transformation of practice. A comparison between the lived experience of stakeholders and the ideas emergent within literature provides the basis for the descriptive assessment of praxis within a discipline field. This assessment of praxis informs the further design of curriculum as it shapes responses to the latter stages of the process.

\section{Step 2: Mapping of praxis course objectives}

The second step of Intervention Mapping translates the previous exploration of praxis to articulated course aims and objectives. The course aim and curriculum objectives were developed in response to the needs assessment detailed in the first step. Importantly the objectives were designed to reflect the varying demands of the practice setting, reflecting the experience of practice in the identified setting, and also be framed as measurable outcomes of learning. Within this context, it was identified that the praxis course needed to meet the needs of a diverse student cohort from a range of professional disciplines, undertaking workbased learning in a range of practice environments. From the Reference Group discussions, the identified aims of the praxis course were to i) assist students develop new mental health skills in a particular area, ii) review professional understandings and evidence regarding the skills, and iii) develop an advanced level of capability within this identified skill. The expected student learning outcomes were defined and include aspects such as critical reflection and evaluation of individual practitioner skills, application of theory and evidence based interventions, demonstration of interprofessional collaboration, and awareness of individual learning styles and future professional learning goals. The relatively generic nature of the learning outcomes facilitates individual choice of specific outcomes and how students will meet these outcomes.

Further information about the learning objectives can be found in Table 1.

\section{Step 3: Theory-based methods and practical strategies}

In this step, suitable theories, curriculum models and practical strategies that could best meet the praxis aims and learning objectives were identified. The following theory and 
pedagogical approach was identified based on the outcomes and findings from the literature review and the stakeholder Reference Group discussions.

Initially, it was important to identify theories which would underpin the development of curriculum aimed at supporting advanced practitioner learning within the workplace setting. It is clear that participating in work alone does not necessarily ensure that a person develops high levels of expertise and performance (Ericsson, 2008). Once an acceptable level of performance has been attained, the mere act of engaging in an activity for years does not appear to automatically lead to improvements in performance (Ericsson, 2004). Deliberate Practice Theory (Ericsson, 2008; Ericsson, Krampe, \& Tesch-Römer, 1993) suggests that the acquisition of expert performance can be seen as the result of engagement in deliberate practice activities where the explicit goal is to improve particular aspects of a particular work activity or performance. As such, this theoretical approach was identified as particularly relevant to inform the development of advanced practitioner skills.

Deliberate practice research was initially concerned with domains and practices such as sports, typing, chess and music (Charness, Tuffiash, Krampe, Reingold, \& Vasyukova, 2005; Ericsson et al., 1993; Keith \& Ericsson, 2007) but has recently been examined in the acquisition of expertise in nursing (Chee; Liou, Chang, Tsai, \& Cheng, 2013) and medicine (van de Wiel, Van den Bossche, Janssen, \& Jossberger, 2011). Research into deliberate practice indicates that the amount of high quality practice accumulated during an individual's career is closely related to their attained performance (Ericsson \& Lehmann, 1996). However, not all experiences or practices are seen as equally helpful in developing skills and expertise (Plant, Ericsson, Hill, \& Asberg, 2005) and explicit goals focussed on particular aspects of a particular work activity or performance are required (Ericsson et al., 1993). Learning goals and activities are typically individually designed by a practitioner/mentor and the specific goals and learning activities will differ for each person (Plant et al., 2005). Within Deliberate Practice Theory, it is the motivation of the practitioner which drives the learning behaviours and activities and this theoretical approach has been utilised to underpin the development of the praxis curriculum.

Within the work-based learning model used in the development of advanced practitioners, the holistic nature of the learning experience (extending beyond discipline boundaries) means that students are required to recognise knowledge presented in different and unfamiliar ways and develop the skills to learn from the experiences encountered (Brodie 
\& Irving, 2007). In addition, there is agreement across many disciplines that ideally, instruction for complex skill learning should centre on authentic tasks, should be adaptive to the individual learner's needs and capacity and should support and motivate learners in acquiring the ability to plan, monitor and evaluate their own learning process (Van Gog, Ericsson, Rikers, \& Paas, 2005). Van Gog, et al. (2005) argue that the first task in deliberate practice is to identify the aspects of the skilled performance required, as well as performance criteria associated with the different levels of expertise. Tasks could then be developed or identified that improve performance on these aspects.

Learning-centred principles are important elements in curriculum design as tasks, roles and identities of modern workers changes to meet the needs of an ever-changing professional environment (Kuhn, 2008). Models of work-based learning, for example Brodie and Irving (2007), also highlight the necessity of a structured and deliberate approach to learning in and through practice. Within Brodie and Irving's model, the following elements of student understanding and learning are seen as important: i) the student knows what they are learning (implies change) and how to do it most effectively (style, approach and fitness for purpose); ii) the student can recognise when they have learnt (description and reflection about the learning); iii) they are able to identify what has been learnt (analysis and evaluation of the learning); (iv) they know what the learning is informed by (its validity and evidence); and (v) the students can recognise what they need to learn (future learning). Billett (2002) identifies workplace activities as inherently pedagogic, shaped by participant thinking, acting and engaging in goal-directed activities.

Considering these elements of work-based learning, it was concluded to be important that the course design provided opportunities for the students to shape their own learning as well as promoting the student's awareness of their own leaning and ability to reflect on their behaviours and learning.

In considering learning through work it is also important to consider the concept of expertise and how it is developed. An important feature of expertise is the preparedness and ability of learners to plan for long-term or continuous improvement (Tagg, 2007). The ability to identify and participate in ongoing professional practice learning is seen as an important skill for all health practitioners and was an intended learning outcome of the course design. Ideally, students in this course would develop an ongoing ability to shape their own learning processes, that is identify areas or improvement, seek out activities and plan, monitor and 
evaluate this process (Zimmerman, 2002). Given the postgraduate, professional focus of this program, it would be desirable for all students to have the skills to identify and plan for future professional learning on completion of the course. As such, within the course design the construct of expertise and future learning elements was embedded in the discourse of the learning and made explicit within the assessment tasks students completed.

\section{Step 4: Praxis course design}

The fourth step in the Intervention Mapping approach is the development of the course content, delivery and assessment items. From the established aims and learning objectives, the praxis curriculum was developed and subsequently discussed by the stakeholder Reference Group to assess strengths and weaknesses. The assessment items and aspects of course delivery were refined in response to feedback from the stakeholder Reference Group. Final assessment items include (Table 1):

\section{a) Praxis learning plan}

The praxis learning plan is a negotiated, written agreement between the student and supervisor/mentor outlining the learning goals and learning activities the student will undertake whilst participating in the course (Martin, Rees, Edwards, \& Paku, 2012). It is the document that 'drives' the praxis and can serve as a reference for reflection on the student's progress and learning. Students are required to spend significant preparation time, discussing their learning needs and goals with their workplace, identifying appropriate mentors or experts in the field to assist them with their learning and liaising with university staff and mentors to develop a learning plan with clear activities and outcomes for the praxis and meet course requirements. This document ensures that the praxis is structured, monitored and remains focused on the learning objectives. Students are expected to have identified their learning goals and completed the praxis learning plan prior to the commencement of the semester.

\section{b) Observation of the setting report}

The purpose of the observation of setting report is for the student to develop and demonstrate a good understanding of the agency, its client group and community, the professional practice of the staff and the student's role within this context. It is a report aimed at demonstrating an understanding of the purpose, role and functions of the agency and 
the values, frameworks and relationships that the workers operate within. This is a 10001500 word report submitted prior to the completion of the praxis course.

\section{c) Praxis learning portfolio}

Portfolios are increasingly being used by practitioners to document or record their developing skills and knowledge as they progress in their career or academic program. Scholes et al. (2004) define a portfolio as something that 'captures learning from experience, enables an assessor to measure student learning, acts as a tool for reflective thinking, illustrates critical analysis skills and evidence of self-directed learning and provides a collection of detailed evidence of a person's competence' (pg 595). The aim of the student portfolio is to assist the student understand what they have learnt, as well as how they learnt it. Students are requested to use a format which best suits their style and focus of description (e.g. word document, e-portfolio, blog). It has been suggested that there has been an evolution in the development of purpose of portfolios from assessment of practice to assessment of the deliberative enquiry into practice (Jones, 2010; Lyons, 2003). It is hoped that by developing skills to document evidence in practice through the portfolio, students will enhance their ability to reflect on experiences or episodes of learning and use this information in their future planning.

\section{d) Supervisors report}

Brodie and Irving (2007) identify that the assessment of student capability is problematic, particularly when there is a diverse range of workplaces and skills being assessed. As the intended overall outcome of the praxis course is the demonstration of new skills in advanced practice, it is important that some form of assessment of capability is included. The above assessment items rely on evidence provided by students. Brodie and Irving (2007, p. 17) suggest that rather than assessing capability, relying on student assessment alone assesses a student's ability to articulate their capability.

Workplace mentors are in constant contact with the student and university throughout the praxis and are an alternative source of information regarding a student's performance. There is argument that issues of reliability and validity are dependent on the supervisor's level of assessment skills (Costley, 2007), but despite these difficulties, there is a need to look beyond evidence provided by students and the inclusion of feedback from the workplace supervisor or mentor may still be useful. 
Within the mental health praxis course, the supervisor or mentor is asked to provide comment and a rating on a three point scale (Highly Satisfactory, Satisfactory or Unsatisfactory) on the following areas of student performance:

- achievement of learning goals

- ability to attend to basic work requirements (e.g. time management, awareness of ethical requirements)

- interactions with others (e.g. communication with other staff and consumers)

- $\quad$ skill development (e.g. specific skills demonstrated)

It is hoped that by focusing the supervisor/mentor feedback on these general areas of student participation in the praxis, the required flexibility to meet the needs of different skills and contexts is met and assessment information about the student's engagement in learning is obtained. Information about skills developed and demonstrated is also obtained. The assessment items have been designed to align with the course learning objectives (Table 1).

\section{INSERT TABLE 1 HERE}

\section{Step 5: Praxis implementation plan}

The fifth stage of the Intervention Mapping Approach focuses on the implementation of the new curriculum. This is both through the development and execution of an implementation plan. Curriculum implementation involves putting the curriculum into action and includes maintenance through the involvement of support and monitoring of feedback (Pinar, 2012). The course was introduced for student enrolment in semester 2, 2013. The course is a core requirement for all students enrolled in the Masters qualification and is undertaken in their final semester of study. Six students enrolled and completed the praxis course in semester 2, 2013. The course will be available to students in both semesters in an ongoing manner.

Feedback from students and teaching staff involved in the initial implementation of the praxis course, indicated that the planning process was rushed due to tight semester timeframes. As the planning process was seen as essential to ensure identification of appropriate learning goals, student mentors and to establish supportive workplace relationships, a new preparation for praxis course was introduced in semester 1,2014 . This course captures students eligible for enrolment in the praxis course the following semester 
and requires them to begin planning the praxis with the course convenor and their workplaces, and identify learning goals and potential mentors. The learning plan is negotiated and finalised during the preparation course to ensure that all students are able to commence the praxis activities at the start of the following semester.

\section{Step 6: Praxis evaluation plan}

The sixth step in the Intervention Mapping approach is to formulate an evaluation plan. This plan should be developed concurrently with steps 4 and 5, but should also account for the intended learning outcomes and foci determined in the early stages of the design development. This step in the Intervention Mapping process enables thoughtful and formative evaluation to ascertain to what degree the decisions, assumptions and expectations have been realised and whether changes are needed (Bartholomew, Parcel, \& Kok, 1998). The following is an outline of the evaluation plan.

The overall goal of the praxis course evaluation is to understand student outcomes and explore factors which supported or limited student learning within this pedagogical model. In health education research, qualitative methods have increasingly been seen as an effective way of evaluating aspects of educational outcomes (DiCicco-Bloom \& Crabtree, 2006). As this is an exploratory study, a qualitative methodology was chosen and a combination of qualitative methods - in-depth analysis of reflective portfolio assessment items and semistructured interviews and follow-up interviews are used. An interpretivist/constructivist research approach underpinned by a constant comparative method is used to gather in-depth descriptions from students and mentors and rich data about their experiences of participating in the praxis course (Cohen \& Manion, 1994). The student and mentor sample will be drawn from the praxis course over three semesters. Ethics approval for the evaluation was granted on $5^{\text {th }}$ November, 2013 (HSV/02/13/HREC).

To examine the experiences and factors important to stakeholders in student learning through a praxis model, a number of data sources will be explored in the evaluation:

a) Semi-structured interview: At the completion of the course delivery in semester 2 $2013(n=4)$, semester $12014(n \approx 1)$, and semester $22014(n \approx 5)$, (once final grades are established), all student and mentor participants are invited to participate in a faceto-face or telephone semi-structured interview about their experiences and factors which have impacted on student learning. Participation will be voluntary and informed 
consent will be obtained from all participants. A semi-structured interview guide has been developed and questions are broad to encourage active reflection through the open questioning. Demographic data for each participant is collected including gender, age, years of experience in current workplace, years of experience in the mental health workforce, previous qualifications and job description.

All interviews are undertaken by one researcher and are audio recorded. Interviews are transcribed by a third party and de-identification of information occurs in the transcription phase.

b) Portfolio: A qualitative analysis of the portfolio praxis reflections that students complete as part of the assessment requirements for the praxis course.

c) Six month follow up interview: Students who had enrolled in semester 2, 2013 course and completed an initial interview will be invited to participate in a second follow up interview six months after completion of the praxis course to determine if there were any long-term outcomes from the course.

The data from the interviews transcriptions and portfolio assessment items will be analysed with the use of NVivo software. Data will be classified and interpreted into coded or condensed themes and a second researcher will independently code the data to minimise bias in the analysis.

The flexible nature of the Intervention Mapping process enables the project team to return to and reconsider earlier steps based on the outcomes or difficulties encountered. Bartholomew et al. (2010) see the planning process as iterative rather than linear, allowing movement back and forth between tasks and steps. This flexibility will allow the course to be changed in response to issues identified after each implementation phase, and also allow the ongoing evaluation of these changes to be incorporated into the process.

\section{Discussion}

Whilst there is a growing interest in the implementation of postgraduate, coursework programs within Australia, the diversity in educational designs, teaching methods and 
technology present significant challenges to the higher education sector (Clark, 2004). We have presented the case of the Intervention Mapping approach as providing a structured approach to curriculum design and described how this approach was used to develop a workbased praxis course for postgraduate mental health students. Curriculum design, particularly within work-based experiences, is often undertaken in an ad hoc manner in response to personal experiences and anecdotal evidence. That is, curriculum leaders (e.g. lecturers, course coordinators) adjust and reform curriculum, particularly through enacting curriculum in workplace settings, in response to isolated events without a concerted consideration of broader design principles and guidance, with the enacted curriculum emerging as an 'accidental' form of interpretation, past experience and perceived expertise (Billet, 2011b). Such an 'accidental' approach is not necessarily a negative (Riley, 2002), however, it does rely heavily upon existing pedagogical knowledge, teacher expertise and is divorced from the increasing demands of accountability and regulation. Strengths of the Intervention Mapping Approach include that the opinions of stakeholders, as well as evidence-based approaches, are integrated to ensure that the curriculum is relevant to its target audience and that the curriculum design reflects the intent and purpose of the learning experience. These have been important elements in the design of the praxis curriculum, which needed to respond to the diverse needs of a professional / advanced practitioner student cohort. The Intervention Mapping Approach allowed the curriculum developers to explore and integrate a wide-range of information to meet the needs of a wide-range of students and work settings.

In addition, the inclusion of an evaluation plan ensures that data is collected to inform required changes or updates to the curriculum, as well as adding to the work-based learning and health education literature. The Intervention Mapping Approach enables thoughtful, iterative and interactive approaches to the development of programs and allows the development of a clear plan of action to achieve a goal (Bartholomew et al., 1998). Often approaches in curriculum design ignore detailed evaluation of outcomes, relying on coarse measures of student satisfaction and grades. Within this approach there is a focus on detailed evaluation that considers outcomes for all stakeholders and considers the role of the postgraduate program in meeting the needs of industry.

From the first implementation of the course, it was clear that development of the learning plan was a complex task for students, requiring considerable support from the University course convenors and student mentors. To manage this process well, significant planning time was needed and the praxis preparation course was introduced to meet this need. 
Although the Intervention Mapping process is laid out in a series of steps, there is flexibility in the approach to allow for the revision of steps as new information is acquired.

A possible limitation to using the Intervention Mapping approach is that it is often seen as time consuming and resource intensive (Munir et al., 2013; Schaalma \& Kok, 2009). While this approach did require the curriculum developer to spend additional time in the planning process, the clear step-by-step approach provided guidance to the project and ensured that the outcome was relevant and theoretically sound.

While Intervention Mapping has its origin in public health, and in particular health promotion programs, the results of this study show that this approach can be useful in the development of health education curriculum within the higher education sector. The framework with its clear step-by-step approach allowing the integration of stakeholder need, theoretical frameworks and practical applications, was found to be a useful tool in the development of the mental health praxis course. Just as importantly there is emerging evidence, through the evaluation, that this approach to curriculum design has created a course that is responsive to the needs of students' future workplaces better preparing graduates for continual improvement in professional practice. Also through engagement with the process there is some evidence that stakeholders and workplaces have reimagined their own learning and approaches to ongoing development. Therefore, although Intervention Mapping provides a clear and comprehensive approach to curriculum design it may also have a reciprocal aspect in reshaping stakeholder understandings and practices. This aspect requires further investigation.

\section{Acknowledgements}

The author acknowledges the funding received from a Griffith University Learning and Teaching grant to enable this development work to be undertaken.

\section{References}

Australian Institute of Health and Welfare. (2012). Australia's health 2012. (Cat. no. AUS 156). Canberra: AIHW Retrieved from http://www.aihw.gov.au/WorkArea/DownloadAsset.aspx?id=10737422169.

Barnett, R. (2012). Learning for an unknown future. Higher Education Research \& Development, 31(1), 65-77. doi: 10.1080/07294360.2012.642841

Bartholomew, L. K., Parcel, G. S., \& Kok, G. (1998). Intervention Mapping: A process for developing theory and evidence-based health education programs. Health Education \& Behavior, 25(5), 545-563. doi: 10.1177/109019819802500502 
Bartholomew, L. K., Parcel, G. S., \& Kok, G. (2010). Planning Health Promotion Programs: An Intervention Mapping Approach (3rd Edition). Hoboken, NJ, USA: Jossey-Bass.

Begg, S., Vos, T., Barker, B., Stevenson, C., Stanley, L., \& Lopez, A. (2007). Burden of disease and injury in Australia, 2003: Australian Institute of Health and Welfare (AIHW).

Billett, S. (2002). Critiquing workplace learning discourses: Participation and continuity at work. Studies in the Education of Adults, 34(1), 56-67.

Billett, S. (2008). Emerging Perspectives on Workplace Learning. In S. Billett, C. Harteis \& A. Eteläpelto (Eds.), Emerging Perspectives of Workplace Learning (pp. 1-12). Rotterdam: Sense.

Billett, S. (2010). Lifelong learning and self: work, subjectivity and learning. Studies in Continuing Education, 32(1), 1-16. doi: 10.1080/01580370903534223

Billett, S. (2011a). Curriculum and pedagogic bases for effectively integrating practice-based experiences. Strawberry Hills: Australian Learning and Teaching Council.

Billett, S. (2011b). Workplace curriculum: practice and propositions. In F. Dochy, D. Gijbels, M. Segers \& P. VandenBossche (Eds.), Theories of learning for the workplace. Building blocks for training and professional development programs (pp. 17-36). London: Routledge.

Boud, D. (2010). Relocating reflection in the context of practice. In H. Bradbury, N. Frost, S. Kilminster \& M. Zukas (Eds.), Beyond Reflective Practice: New Approaches to Professional Lifelong Learning (pp. 25-36). Oxon: Routledge.

Brodie, P., \& Irving, K. (2007). Assessment in work-based learning: investigating a pedagogical approach to enhance student learning. Assessment \& Evaluation in Higher Education, 32(1), 11-19. doi: 10.1080/02602930600848218

Cairns, L., \& Malloch, M. (2011). Theroies of Work, Place and Learning: New Directions. In M. Malloch, L. Cairns, K. Evans \& B. O'Connor (Eds.), The SAGE Handbook of Workplace Learning (pp. 3-16). London: SAGE Publications.

Charness, N., Tuffiash, M., Krampe, R., Reingold, E., \& Vasyukova, E. (2005). The role of deliberate practice in chess expertise. Applied Cognitive Psychology, 19(2), 151-165.

Chee, J. Clinical simulation using deliberate practice in nursing education: A Wilsonian concept analysis. Nurse Education in Practice. doi: http://dx.doi.org/10.1016/j.nepr.2013.09.001

Clark, C. S. (2004). Complexity in nursing education: Examples of the paradigm.World Futures, 60(5-6), 371-388. doi: 10.1080/02604020490468348

Cohen, L., \& Manion, L. (1994). Research Methods in Education (4th ed.). London: Routledge.

Connor, M. J. (2004). The practical discourse in philosophy and nursing: an exploration of linkages and shifts in the evolution of praxis. Nursing Philosophy, 5(1), 54-66.

Cornélio, M. E., Godin, G., Rodrigues, R., Agondi, R., Spana, T., \& Gallani, M.-C. (2013). Development of the SALdável programme to reduce salt intake among hypertensive Brazilian women: an intervention mapping approach. European Journal of Cardiovascular Nursing, 12(4), 385-392. doi: 10.1177/1474515112461324

Costley, C. P. (2007). Work-based learning assessed as a field or a mode of study. Assessment \& Evaluation in Higher Education, 32(1), 21-33. doi: 10.1080/02602930600848267

Dalum, P., Schaalma, H., \& Kok, G. (2012). The development of an adolescent smoking cessation intervention-an Intervention Mapping approach to planning. Health education research, 27(1), 172-181.

DiCicco-Bloom, B., \& Crabtree, B. (2006). The qualitative research interview. Medical Education, 40(4), 314-321. doi: 10.1111/j.1365-2929.2006.02418.x 
Ericsson, K. (2004). Deliberate practice and the acquisition and maintenance of expert performance in medicine and related domains. Academic Medicine, 79(10), S70-S81.

Ericsson, K. (2008). Deliberate Practice and Acquisition of Expert Performance: A General Overview. Academic Emergency Medicine, 15(11), 988-994. doi: 10.1111/j.15532712.2008.00227.x

Ericsson, K., Krampe, R. T., \& Tesch-Römer, C. (1993). The role of deliberate practice in the acquisition of expert performance. Psychological review, 100(3), 363.

Ericsson, K., \& Lehmann, A. C. (1996). Expert and exceptional performance: Evidence of maximal adaptation to task constraints. . Annual review of psychology., 47(1), 273305.

Fowler, C., \& McGarry, D. (2011). Praxis: The Essential Nursing Construct Evidence-Based Practice in Nursing Informatics: Concepts and Applications (pp. 40-50): IGI Global.

Hager, P. (2011). Theories of Workplace Learning. In M. Malloch, L. Cairns, K. Evans \& B. O'Connor (Eds.), The SAGE Handbook of Workplace Learning (pp. 17-31). London: SAGE Publications.

Health Workforce Australia. (2011). National Health Workforce Innovation and Reform Strategic Framework for Action 2011-2015. Adelaide: Retrieved from https://www.hwa.gov.au/sites/uploads/hwa-wir-strategic-framework-for-action201110.pdf.

Healy, A., Perkmann, M., Goddard, J., \& L., K. (2014). Measuring the impact of universitybusiness cooperation. Luxembourg: Publications Office of the European Union.

Higgs, J., Loftus, S., \& Trede, F. (2010). Education for Future Practice. In J. Higgs, D. Fish, I. Goulter, S. Loftus, J. Reid \& F. Trede (Eds.), Education for Future Practice (Vol. 3, pp. 3-14). Rotterdam: Sense Publishers.

Jones, E. (2010). Enhancing professionalism through a professional practice portfolio. Reflective Practice, 11(5), 593-605. doi: 10.1080/14623943.2010.516970

Kandiko, C., \& Blackmore, P. (2012). The networked curriculum. In C. Kandiko \& P. Blackmore (Eds.), Strategic curriculum change: Global trends in universities (pp. 320). Abingdon: Routledge.

Keith, N., \& Ericsson, K. (2007). A deliberate practice account of typing proficiency in everyday typists. Journal of Experimental Psychology: Applied, 13(3), 135.

Kerry, T., \& Kerry, C. (2010). Theoretical perspectives. In T. Kerry (Ed.), Meeting the challenges of change in postgraduate education (pp. 11-28). London: Continuum International Publishing Group.

Khan, M. A., \& Law, L. S. (2015). An Integrative Approach to Curriculum Development in Higher Education in the USA: A Theoretical Framework. International Education Studies, 8(3), p66.

Kok, G., Schaalma, H., Ruiter, R. A. C., Van Empelen, P., \& Brug, J. (2004). Intervention Mapping: protocol for applying health psychology theory to prevention programmes. Journal of Health Psychology, 9(1), 85-98. doi: 10.1177/1359105304038379

Kuhn, L. (2008). Complexity and Educational Research: A critical reflection. Educational Philosophy and Theory, 40(1), 177-189. doi: 10.1111/j.1469-5812.2007.00398.x

Lester, S., \& Costley, C. (2010). Work-based learning at higher education level: value, practice and critique. Studies in Higher Education, 35(5), 561-575. doi: 10.1080/03075070903216635

Liou, S.-R., Chang, C.-H., Tsai, H.-M., \& Cheng, C.-Y. (2013). The effects of a deliberate practice program on nursing students' perception of clinical competence. Nurse Education Today, 33(4), 358-363. doi: http://dx.doi.org/10.1016/j.nedt.2012.07.007

Lloyd, J. J., Logan, S., Greaves, C. J., \& Wyatt, K. M. (2011). Evidence, theory and context-using intervention mapping to develop a school-based intervention to prevent obesity 
in children. The international journal of behavioral nutrition and physical activity, 8(73), 73-73.

Lyons, N. (2003). Advancing the scholarship of teaching and learning: Reflective portfolio inquiry in higher education-a case study of one institution. Irish Educational Studies, 22(1), 69-88.

Martin, A., Rees, M., Edwards, M., \& Paku, L. K. (2012). An organization overview of pedagogical practice in work-integrated education. Asia-Pacific Journal of Cooperative Education, 13(1), 23-37.

Mattsson, M., \& Kemmis, S. (2007). Praxis-related research: serving two masters? Pedagogy, Culture \& Society, 15(2), 185-214. doi: 10.1080/14681360701403706

McCormack, B., \& Manly, K. (2004). Evaluating practice development. In R. Garbett, K. M. N. Manley \& B. McCormack (Eds.), Practice Development in Nursing (pp. 83-117). Oxford: Blackwell Pub.

Morris, C., \& Blaney, C. (2010). Work-based Learning. In T. Swanwick (Ed.), Understanding Medical Education: Evidence, Theory and Practice (pp. 69-82): Wiley-Blackwell.

Munir, F., Kalawsky, K., Wallis, D. J., \& Donaldson-Feilder, E. (2013). Using intervention mapping to develop a work-related guidance tool for those affected by cancer. BMC Public Health, 13(1), 6-6.

Orrell, J., \& Higgs, J. (2012). Social and political change: Implications for profesisonal and practice-based university education. In J. Higgs, R. Barnett, S. Billett, M. Hutchings \& F. Trede (Eds.), Practice-based education: Perspectives and strategiesPractice, Education, Work and Society (Vol. 6). Rotterdam: Sense Publishers.

Pinar, W. (2012). What Is Curriculum Theory? (2nd ed.). London: Routledge.

Plant, E. A., Ericsson, K. A., Hill, L., \& Asberg, K. (2005). Why study time does not predict grade point average across college students: Implications of deliberate practice for academic performance. Contemporary Educational Psychology, 30(1), 96-116.

Plewa, C., Galán-Muros, V., \& Davey, T. (2014). Engaging business in curriculum design and delivery: a higher education institution perspective. Higher Education, 1-19. doi: 10.1007/s10734-014-9822-1

Raelin, J. A. (2007). Toward an epistemology of practice. Academy of Management Learning \& Education, 6(4), 495-519. doi: 10.5465/amle.2007.27694950

Riley, T. (2002). The Accidental Curriculum. The Journal of the Assembly for Expanded Perspectives on Learning, 8: Iss. 1, Article 8, 61-70. Retrieved from JAEPL website: http://trace.tennessee.edu/jaepl/vol8/iss1/8

Schaalma, H., \& Kok, G. (2009). Decoding health education interventions: The times are achangin'. Psychology \& Health, 24(1), 5-9. doi: 10.1080/08870440801995802

Scholes, J., Webb, C., Gray, M., Endacott, R., Miller, C., Jasper, M., \& McMullan, M. (2004). Making portfolios work in practice. Journal of Advanced Nursing, 46(6), 595603. doi: 10.1111/j.1365-2648.2004.03050.x

Smith, C. (2011). Evaluating the quality of work-integrated learning curricula: a comprehensive framework. Higher Education Research \& Development, 31(2), 247262. doi: $10.1080 / 07294360.2011 .558072$

Stewart, V., Fielden, J., Harris, M., \& Wheeler, A. (2012). Making mental health practitioners workforce ready. The Journal of Mental Health Training, Education and Practice, 7(3), 124-132. doi: 10.1108/17556221211269938

Tagg, J. (2007). Learning outcomes and the development of expertise. On the Horizon, 15(2), 89-98. doi: http://dx.doi.org/10.1108/10748120710757325

Trede, F., \& McEwen, C. (2012). Developing a critical professional identity: Engaging self in practice. In J. Higgs, R. Barnett, S. Billett, M. Hutchings \& F. Trede (Eds.), Practice- 
based education: Perspectives and strategies (pp. 27-40). Rotterdam: Sense Publishers.

van de Wiel, M., Van den Bossche, P., Janssen, S., \& Jossberger, H. (2011). Exploring deliberate practice in medicine: how do physicians learn in the workplace? Advances in health sciences education, 16(1), 81-95.

Van Gog, T., Ericsson, K. A., Rikers, R. M., \& Paas, F. (2005). Instructional design for advanced learners: Establishing connections between the theoretical frameworks of cognitive load and deliberate practice. Educational Technology Research and Development, 53(3), 73-81.

van Oostrom, S. H., Anema, J. R., Terluin, B., Venema, A., de Vet, H. C. W., \& van Mechelen, W. (2007). Development of a workplace intervention for sick-listed employees with stress-related mental disorders: Intervention Mapping as a useful tool. BMC health services research, 7(1), 127-127.

van Rijssen, H. J., Schellart, A. J. M., Anema, J. R., de Boer, W. E. L., \& van der Beek, A. J. (2011). Systematic development of a communication skills training course for physicians performing work disability assessments: from evidence to practice. BMC medical education, 11(1), 28-28.

Weller, S. (2012). Achieving curriculum coherence: Curriculum design and delivery as a social practice. In P. Blackmore \& C. Kandiko (Eds.), Strategic curriculum change: Global trends in universities (pp. 21-33). Abingdon: Routledge.

Wheeler, A., Fowler, J., \& Hattingh, L. (2013). Using an Intervention Mapping Framework to Develop an Online Mental Health Continuing Education Program for Pharmacy Staff. Journal of Continuing Education in the Health Professions, 33(4), 258-266.

Zimmerman, B. J. (2002). Achieving academic excellence: A self-regulatory perspective. In M. Ferrari (Ed.), The pursuit of excellence through education. (pp. 84-110). Hillsdale: Erlbaum. 
Table 1: Alignment of assessment items to learning objectives

\begin{tabular}{|c|c|c|c|c|}
\hline \multirow[b]{2}{*}{ Learning Objective } & \multicolumn{4}{|c|}{ Assessment item } \\
\hline & 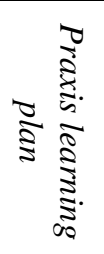 & 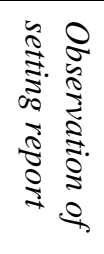 & 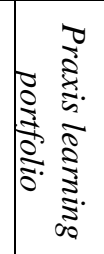 & 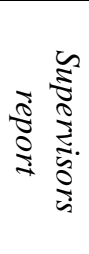 \\
\hline $\begin{array}{l}\text { 1. Describe the importance of being a competent practitioner } \\
\text { through critical reflection and evaluation of skills and abilities } \\
\text { in relation to the workplace and professional requirements; }\end{array}$ & $X$ & $X$ & $X$ & $\mathrm{X}$ \\
\hline $\begin{array}{l}\text { 2. Apply theoretical concepts to practice situations and further } \\
\text { develop mental health assessment, intervention planning and } \\
\text { relationship building skills, incorporating awareness of } \\
\text { diversity; }\end{array}$ & $\mathrm{X}$ & & $\mathrm{X}$ & $X$ \\
\hline $\begin{array}{l}\text { 3. Engage in the processes, practices and considerations of } \\
\text { service delivery and be able to reflect on your own } \\
\text { contribution to these; }\end{array}$ & $X$ & $\mathrm{X}$ & $X$ & \\
\hline $\begin{array}{l}\text { 4. Demonstrate ability to work within a multidisciplinary team } \\
\text { and engage in inter-professional, consumer and carer } \\
\text { collaboration and communication; }\end{array}$ & & & & $X$ \\
\hline $\begin{array}{l}\text { 5. Demonstrate an awareness of your own learning styles and } \\
\text { identify future professional learning goals. }\end{array}$ & & & $X$ & $\mathrm{X}$ \\
\hline
\end{tabular}

